\title{
Serological evaluation of a measles, mumps, and rubella vaccine
}

\author{
C M ROBERTSON, V J BENNETT, N JEFFERSON, AND R T MAYON-WHITE \\ Department of Community Medicine, Oxfordshire Health Authority, Headington, Oxford
}

SUMmary Combined measles, mumps, and rubella vaccination is soon to become available in Britain in the routine immunisation programme. A controlled study was performed in 319 children, aged 13 months, to assess the antibody response and clinical reactions to a new combined measles, mumps, and rubella vaccine in comparison with a single component measles vaccine. In the children who received the combined vaccine, seroconversion was established in $93 \%$ for measles, $99 \%$ for rubella, and $100 \%$ for mumps. In the children who received the single measles vaccine, seroconversion was established in $92 \%$ for measles and in none for rubella and mumps. There was no increase in clinical reactions after the measles, mumps, and rubella vaccine compared with the measles vaccine.

These results suggest that this combined vaccine would be effective and safe in a British population and give further support for the introduction of the combined measles, mumps, and rubella vaccine to Britain.

The inadequate immunisation policies in Britain, particularly immunisations against measles and rubella, have had considerable coverage in recent literature. ${ }^{1-7}$ By 1984 , the national measles immunisation rate had reached only $63 \%{ }^{8}$ and there is still significant morbidity from the disease. Selective immunisation of schoolgirls and non-immune adult women against rubella has reduced the incidence of congenital rubella syndrome, but there is evidence that immunisation of all young children is needed to reduce this further. ${ }^{9} 10$

It has been suggested that a new strategy for immunisation against measles, mumps, and rubella should be introduced into Britain with the aim of eradicating all three diseases. ${ }^{12} \mathrm{~A}$ combined measles, mumps, and rubella vaccine has been used routinely in the United States since the 1970s and in Sweden and Finland since 1982. It has been shown to be safe and effective. British public opinion is still very sensitive to reports of adverse reactions to the pertussis vaccine and it is difficult to predict the response to another 'new' vaccine. It has been postulated that parents might find a combined vaccine a more attractive option than the single measles vaccine. ${ }^{129}$

The Department of Health has recently (April 1987) agreed to the introduction of the combined measles, mumps, and rubella vaccine in principle. It is therefore important to establish the efficacy and safety of the combined vaccine in Britain. Before the vaccine is used routinely in this country it is also vital that its potential uptake is assessed because an uptake of $85 \%$ is needed to achieve herd immunity. ${ }^{9}$ We report the results of a controlled trial of a new combined vaccine in comparison with a single measles vaccine in a British population. We assessed the rate of seroconversion and the occurrence of clinical reactions in 319 children aged 13 months. We were also interested in the general response to the trial and the combined vaccine.

\section{Subjects and methods}

Before the trial started all health visitors, general practitioners, and clinical medical officers were informed of the trial and the purpose of the combined vaccine. Names of children due to receive the measles vaccine within the following 2-3 months were obtained from the Oxfordshire Health Authority immunisation computer programme. The parents of all children attending various large clinics throughout Oxfordshire were approached by letter. The letter gave a brief explanation of the study and parents were asked to complete a short question- 
naire. If the parents expressed an interest in the study they were visited at home by the investigators and the study was explained in more detail. If they agreed for their child to participate they completed a written assent.

The parents were offered the choice of which vaccine their child would receive (the combined measles, mumps, and rubella vaccine or the single measles vaccine). Random allocation was planned if the parents had no preference. Children with a definite history of measles, mumps, or rubella were excluded from the trial, as were any children who had a history of convulsions, immunosuppression, or severe allergy to egg, neomycin or kanamycin. The immunisation was postponed if the child had an acute febrile illness.

The children were immunised at the age of 13 months. The combined vaccine used contained the Schwarz (measles), Urabe AM/9 (mumps), and the Wistar RA 27/3 (rubella) live attenuated virus strains. The single measles vaccine contained the Schwarz strain. The vaccines were reconstituted immediately before use with $0.5 \mathrm{ml}$ of diluent and administered into the anterolateral aspect of the upper thigh. Both vaccines were produced by Institut Merieux. A venous blood sample $(1.5 \mathrm{ml})$ was taken immediately before the immunisation and then again about six weeks later. Parents were informed of the nature and timing of possible reactions and were asked to complete a diary, recording any symptoms or signs in the child (regardless of whether they thought it was caused by the vaccine). The parents assessed the child's temperature by touch and recorded a fever if the child felt hotter than usual.

All serological assays were performed in the laboratories of Institut Merieux in Lyon, France. Before testing the samples were stored at -20$)^{\circ} \mathrm{C}$ and transported to the laboratories on dry ice. The assays were performed under code so that the laboratory did not know which vaccine had been given.

The measles and rubella antibody titres were determined by haemagglutinin inhibition techniques. The initial dilution was 1 in 10 . The mumps antibody titres were determined by the enzyme linked immunosorbent assay (ELISA) using the Behring kit. The initial dilution was 1 in 80. The serological results for each child were sent to the child's parents and reimmunisation was offered to those who had not seroconverted.

Statistical analysis of the incidence of clinical reactions in the two vaccine groups was compared by $\chi^{2}$ with Yates's correction.

The trial was approved by the local ethics committee.

\section{Results}

Letters were sent to 904 parents of whom $642(71 \%)$ returned the questionnaires. Of the 642 replies, 362 $(40 \%$ of the total letters sent) expressed an interest in participating in the trial, $260(29 \%)$ did not want to participate, and $20(2 \%)$ had moved from the area.

Of the 362 children whose parents were initially interested in the trial, 27 were excluded for various medical reasons and 20 parents changed their mind about participating. This left 315 children who were recruited into the trial. A further four children who had been directly referred by health visitors were also recruited. This gave a total of 319 children: $263(82 \%)$ received the measles, mumps, and rubella vaccine and $56(18 \%)$ the single measles vaccine. This meant that $259(29 \%)$ of the original parents approached agreed for their child to be given the combined vaccine in a trial that involved two venepunctures. No parent was undecided as to which vaccine their child should have. The mean age of the children at time of immunisation was 13.1 months. The male to female ratio was $1 \cdot 2: 1$.

\section{SEROLOGICAI. RESULTS}

Preimmunisation blood samples were obtained from $236(90 \%)$ of the children given the measles, mumps, and rubella vaccine and from $52(93 \%)$ of those given the measles vaccine. The numbers of children with preimmunisation antibodies against measles, mumps, and rubella for both vaccine groups are shown in table 1.

Postimmunisation blood samples were obtained from $218(83 \%)$ of the combined vaccine group and $48(86 \%)$ of the measles vaccine group. The average time between the immunisation and the second blood sample was 42 days. Some of the postimmunisation samples were insufficient for all three antibody assays. In the measles vaccine group there was one sample from which just a measles titre was obtained. In the combined vaccine group there was one sample from which only a measles titre was obtained and four samples from which only measles and rubella titres were obtained. The seroconversion rates in initially seronegative children are shown in table 2.

\section{Table 1 Children with preimmunisation antibodies}

\begin{tabular}{lllr}
\hline Vaccine group & No(\%) with antibody present \\
\cline { 2 - 3 } & Measles & Rubella & Mumps \\
\hline Measles $(\mathrm{n}=52)$ & $1(2)$ & $1(2)$ & $5(10)$ \\
Measles, mumps, rubella $(\mathrm{n}=236)$ & $2(1)$ & $5(2)$ & $28(12)$ \\
\hline
\end{tabular}


Seroconversion was taken as a change from a titre of $<10$ preimmunisation to a titre of $\geqslant 20$ postimmunisation for the measles and rubella assays and a change from $<80$ to $\geqslant 160$ in the ELISA mumps assay.

The frequency distribution of the postimmunisation titres and the goemetric mean titres for the measles, mumps, and rubella vaccine and the measles vaccine are shown in the figure.

\section{CLINICAL FINDINGS}

The incidence of signs and symptoms recorded during the three week period postimmunisation are shown in table 3 . Only about $10 \%$ of the children has no symptoms during this time. The most commonly reported symptoms were irritability,

Table 2 Seroconversion rates in initially seronegative children

\begin{tabular}{lccc}
\hline Vaccine group & \multicolumn{2}{l}{ No(\%) who seroconverted } & \\
& Measles & Rubella & Mumps \\
\hline $\begin{array}{l}\text { Measles } \\
\begin{array}{l}\text { Measles, mumps, } \\
\text { and rubella }\end{array}\end{array}$ & $200 / 215(92)$ & $0 / 46$ & $0 / 42$ \\
\hline
\end{tabular}

rash, coryza and fever, followed by lethargy, diarrhoea, anorexia, and cough.

The symptoms of irritability, fever, and rash were most noticeable between the ninth and 13th days after immunisation, however, a suggestion of

Table 3 No (\%) of children with symptoms and signs in the three weeks after immunisation

\begin{tabular}{lcc}
\hline Symptoms and signs & $\begin{array}{l}\text { Measles, mumps, } \\
\text { rubella vacine } \\
(n=26.3)\end{array}$ & $\begin{array}{l}\text { Measles } \\
\text { vacine } \\
(n=56)\end{array}$ \\
\hline Irritability & $175(67)$ & $40(71)$ \\
Rash & $109(41)$ & $23(41)$ \\
Coryza & $104(40)$ & $27(48)$ \\
Fever & $88(34)$ & $16(29)$ \\
Cough & $40(15)$ & $12(21)$ \\
Lethargy & $65(25)$ & $13(23)$ \\
Diarrhoca & $55(21)$ & $10(18)$ \\
Vomiting & $33(13)$ & $7(13)$ \\
Anorexia & $48(18)$ & $14(25)$ \\
Conjunctivitis & $23(9)$ & $5(9)$ \\
Lymphadenopathy & $6(2)$ & 0 \\
Parotitis & $3(1)$ & 0 \\
Local reaction & $14(5)$ & $4(7)$ \\
No symptoms & $33(13)$ & $4(7)$ \\
Child: given paracetamol & $156(59)$ & $29(52)$ \\
$\quad:$ seen by a doctor & $42(16)$ & $11(20)$ \\
\hline
\end{tabular}

No significant differences were found.
Figure Frequency distribution of postimmunisation antibody titres and geometric mean titres (GMT), for the measles, mumps, and rubella vaccine and the measles vaccine. HI=haemagglutinin inhibition. 
clustering between the second and fifth days also occurred. This triad of symptoms, often with associated coryza and sometimes cough, occurred in $38(14 \%)$ of the combined vaccine group and in nine $(16 \%)$ of the measles group. The symptoms of anorexia, lethargy, diarrhoea, and vomiting did not show obvious clustering.

Lymphadenopathy occurred in six $(2 \%)$ and parotitis in three $(1 \%)$ of the children who received the combined vaccine and none of the children who received the measles vaccine. Two children developed appreciable bilateral parotitis associated with fever, irritability, and anorexia. One child developed these symptoms six hours after immunisation and the other 24 days after immunisation. Throat swabs were taken from both of these children and mumps virus was grown from both. The incidence of local reactions for both vaccines was low $(5-7 \%)$; none of these were severe. One febrile convulsion occurred on the ninth day in a child who had received the combined vaccine. One child died four weeks after immunisation with the combined vaccine after an accident that was totally unrelated to the vaccine.

\section{Discussion}

When considering the introduction of a vaccine it is vital that it has been shown to be effective and to have no severe adverse reactions in the population to which it is to be given. Previous studies have examined the measles, mumps, and rubella vaccine in the United States and in Scandinavia, ${ }^{11-15}$ but this is the first study in Britain, and an early study with the Merieux vaccine.

Careful consideration was given to a randomised and double blind study. It was finally decided that many parents would not accept randomisation and not knowing the type of vaccine that had been given to their child, and this would make recruitment difficult and selective. It is appreciated that the results of the clinical reactions might be affected by the parents' choice of vaccine, but the detailed diaries were intended to minimise this possible source of bias. The serological reponses could not have been affected by the open design. It has been previously shown that seroconversion produced by the combined measles, mumps, and rubella vaccine is as good as the seroconversion produced by each of the single components. ${ }^{16}$ This trial confirms this for the measles part of the Merieux vaccine. The seroconversion rates for the measles, mumps, and rubella vaccine are comparable with those of other studies. ${ }^{12-15}$

The overall incidence of signs and symptoms recorded in the three weeks after immunisation was very high in both vaccine groups, causing initial concern. These results can probably be partly explained by the fact that parents recorded all symptoms and signs in the diaries which produced sensitive but not very specific results. Another explanation for the high incidence of symptoms is that children of this age are suffering from many minor coincidental illnessess. Similar results have been found by Vesikari et al. ${ }^{1+}$ They realised that their figures did not indicate an absolute incidence of reactions to the vaccine because there was no placebo group to act as a control. This trial also contained no placebo group, but the measles vaccine group acted as a control. The incidence of reactions from the measles, mumps, and rubella vaccine has been well demonstrated by Peltola and Heinonen in a placebo controlled twin study. ${ }^{17}$ They found the actual incidence of reactions to be very low and some symptoms had a higher incidence in the placebo group. In our study the clustering of symptoms of fever, rash, and irritability at the end of the second week matches the well recorded pattern of reaction to the measles vaccine. We have shown that there is no significant difference in reactions between the measles, mumps, and rubella vaccine and the single measles vaccine, which is already widely accepted in this country.

Two children developed considerable parotitis, associated with fever, anorexia, and irritability and mumps virus was isolated from their throat swabs. Both children had high mumps titres postimmunisation. The abnormal timing of the symptoms in relation to the immunisation suggested that they were more likely to be due to a coincidental mumps infection. Typing of the virus, however, did not differentiate between the wild and the vaccine strains.

Oxfordshire has some of the highest immunisation rates in the country and the parental response to this trial may not be representative of the whole country. It is encouraging, however, that $29 \%$ of the parents approached were willing for their children to be given the measles, mumps, and rubella vaccine as part of a trial which concerned a new vaccine and two venepunctures. During the explanation to obtain assent to the study the parents seemed to understand the purpose of vaccinating young children against measles, mumps, and rubella. This suggests that the introduction of the combined vaccine will be acceptable to parents. It is hoped that an effective campaign to introduce the combined vaccine would make it popular and would also boost the present immunisation rates against measles. When the vaccine is introduced health visitors will play a vital part in ensuring the understanding and acceptance of it among parents. 
As part of this trial health visitors in the area were informed about the measles, mumps, and rubella vaccine. In follow up survey of 106 health visitors, $98(92 \%)$ of them thought that the vaccine should be introduced.

We have shown that this measles, mumps, and rubella vaccine produces an adequate serological response in children aged 13 months and produces no more clinical reactions than measles vaccine alone. We eagerly await the start of the national programme and decisions on the questions of a booster at the age of about 12 years and on the appropriate health education for parents and health service staff.

We would like to thank all the members of the department of community medicine and paediatrics who helped with the study. In particular, we thank Sandy Pitt for her work. Laboratory support was provided by the virology department. We also thank the health visitors and the general practitioners for their support and all the parents who took part in this study for their cooperation.

The study was supported by a grant from Institut Mericux.

\section{References}

' Walker D, Carter H, Jones IG. Measles, mumps and rubella: The need for a change in immunisation policy. $\mathrm{Br}$ Med $\mathrm{J}$ 1986:292:1501-2.

2 Editorial. Measles vaccine once or MMR twice. Lancet 1986;ii: 671 .

3 Campbell AGM. Measles immunisation: why have we failed? Arch Dis Child 1983:58:3-5.

+ Noah ND. Immunisation before school entry: should there be a law? $\mathrm{Br}$ Med J 1987;294:127()-1.

5 Miller CL, Miller E. Rubella vaccination in the UK: time for a complete strategy. Lancet 1985;ii:732.

" Miller CL, Miller E, Sequeira PJL, Cradock-Watson JE, Longson $M$. Wischerg $E$. Effect of selective vaccination on rubella susceptibility and infection in pregnancy. $\mathrm{Br}$ Med $J$ 1985;291:1398-401

${ }^{7}$ Miller CL, Miller E, Waight P. Rubella susceptibility and the continuing risk of infection in pregnancy. $B r$ Med $J$ 1987;294: 1277-8.

* Central Statistical Office. Social trends 16. London: HMSO. 1986:120.

"Anderson RM. Grenfell BT. Control of congenital rubella syndrome by mass vaccination. Lancet $1985 ;$ ii: $827-8$.

10 Anderson RM. May RM. Two stage vaccination programme against rubella. Lancet $1983 ;$ ii: 1416-7.

" Buynak EB, Weibel RE, Whitman JE, Stokes J, Hilleman MR. Combined live measles, mumps and rubella vaccines. JAMA 1969:207:2259-62.

${ }^{12}$ Schwarz AJF, Jackson JE, Ehrenkranz NJ, Ventura A, Schiff GM, Walters VW. Clinical evaluation of a new measles-mumpsrubella trivalent vaccinc. Am J Dis Child 1975;129:1408-12.

13 Weibel ER. Carlson AJ. Villarejos VM. Buynak EB, McLean AA. Hilleman MR. Clinical and laboratory studies of combined measles, mumps and rubella vaccines using the RA $27 / 3$ rubella virus (40979). Proc Soc Exp Biol Med 1980;165:323-6.

It Vesikari T, Ala-Laurila EL, Heikkinen A. Terho A. D'Hondt E. Andre FE. Clinical trial of a new trivalent measles, mumps and rubella vaccine in young children. Am $J$ Dis Child 1984;138:843-7.

15 Christenson B. Bottiger M. Heller L. Mass vaccination programme aimed at eradicating measles. mumps and rubella in Sweden: first experience. Br Med J 1983:287:389-91.

${ }^{16}$ Lerman SJ, Bollinger M, Brunken JM. Clinical and serologic evaluation of measles, mumps and rubella (HPV-77:DE-5 and RA 27/3) virus vaccines, singly and in combination. Pediatrics 1981:68:18-22.

17 Peltola H. Heinonen OP. Frequency of true adverse reactions to measles-mumps-rubella vaccine: a double blind placebo controlled trial in twins. Lancet 1986;i:939-42.

Correspondence to Dr CM Robertson, Department of Community Medicine, Oxfordshire Health Authority, Manor House. Headley Way, Headington. Oxford OX3 9DZ.

Accepted 25 February 1988 